\title{
Política y Dictadura en Neuquén. La Asamblea Permanente por los Derechos Humanos (APDH) y la formación de los jóvenes, 1980-81
}

\author{
Politics and Dictatorship in Neuquén. The Permanent Assembly for Human Rights (APDH) \\ and the training of young people, 1980-81
}

Cecilia Azconegui*

Resumen: Este artículo analiza el rol de la APDH en la formación de los jóvenes en una coyuntura histórica específica de la última dictadura militar argentina, 1980-1981, antes del retorno masivo de la ciudadanía al espacio público posterior a la derrota en la guerra de Malvinas en 1982. Asimismo, indaga sobre el impacto que la pertenencia a esta organización tuvo en la trayectoria de aquellos jóvenes, teniendo en cuenta el cruce entre sus historias de vida, la vigencia del contexto represivo, el perfil político-ideológico de la organización y el alto riesgo que asumían al participar de la misma. Se argumenta que, aún bajo la dictadura militar, la APDH local propició un rol activo y protagónico del joven en la sociedad de cara a modificar su presente y construir su futuro. El carácter creativo de la participación de estos jóvenes en el seno de la organización entrañaba una nueva manera de pensar y de ejercer la participación (y al ciudadano). La reconstrucción y el análisis de algunas trayectorias individuales permite observar que el paso por la APDH propició un proceso de resocialización política y el comienzo de "carreras militantes" que continuaron posteriormente en organizaciones vecinales, mapuces, sindicales y universitarias.

Palabras claves: Derechos humanos; Dictadura; Jóvenes; Política; Neuquén

Abstract: This article analyzes the role of the APDH in the formation of young people in
a specific historical conjuncture of the last Argentine military dictatorship, 1980-1981,
before the massive return of citizenship to the public space following the defeat in the
Malvinas War in 1982. It also inquiries - taking into account the crossing between their life
stories, the validity of the repressive context, the political-ideological profile of the
organization and the high risk they assumed with their participation - about the impact that
belonging to this organization had on the trajectory of those young people. It is argued that
even under the military dictatorship, the local APDH fostered an active and protagonist
role of the youth in society in order to modify its present and build its future. The creative
nature of the participation of these young people within the organization entailed a new
way of thinking and exercising participation (and the citizen). The reconstruction and
analysis of some individual trajectories allows us to observe that the passage through the

* Argentina, doctoranda en Historia. Docente e investigadora en la Facultad de Humanidades de la Universidad Nacional del Comahue-Cehepyc-CLACSO. cazconegui@gmail.com. Este artículo forma parte de una investigación de mayor alcance que analiza, a partir de la experiencia neuquina, la relación entre catolicismo y sociedad en el marco de regímenes autoritarios. 
APDH led to a process of political resocialization and the beginning of "militant careers" that continued later in neighborhood, mapuces, union, and university organizations.

Key words: Human rights; Dictatorship; Young people; Politics; Neuquén

Recibido: 12 mayo 2019 Aceptado: 28 junio 2019

\section{Introducción}

La dictadura institucional de las Fuerzas Armadas que gobernó Argentina en el período 1976-1983 tenía como objetivo central la "reorganización nacional" y para ello llevó adelante una reestructuración del ordenamiento económico, social, político y cultural. Este proceso fue acompañado de una política represiva de las disidencias y la instauración del orden social mediante el terror de Estado. Si bien el accionar represivo tuvo continuidades con la etapa anterior, caracterizada por el progresivo avance de la represión ilegal y de la legalización de la excepcionalidad, el mismo adquirió, en este período, una brutalidad, extensión y sistematicidad inéditas ${ }^{1}$. El sistema represivo constituido por una doble faz de actuación: una visible (legal) y otra clandestina (ilegal) se extendió a todo el territorio. Dentro de este marco general las Fuerzas Armadas consideraron a Neuquén una zona no peligrosa o "fría", a excepción de la franja cordillerana visualizada como en peligro constante por la permanente "infiltración" de militantes sociales y políticos desde Chile, y la existencia de una hipótesis de conflicto con dicho país. A pesar de esta caracterización propia del régimen militar, Scatizza ha demostrado que las Fuerzas Armadas y de Seguridad desplegaron el mismo dispositivo represivo que en el resto del país, aunque con distinto grado de intensidad. Como argumenta el historiador, este accionar se fundamentó en la doble necesidad de eliminar el posible "accionar subversivo" y desalentar cualquier intento similar ya que aunque las organizaciones político-militares no habían elegido la zona como un espacio privilegiado para desarrollar sus acciones armadas, acontecimientos recientes como el Choconazo (1969/70), las puebladas denominadas Cipolletazo (1969) y Rocazo (1972) , y el activo movimiento estudiantil universitario eran indicios claros de la movilización social y política en la región, que podían ser vistos como ámbitos propicios para el "desarrollo subversivo" 2 .

Frente a este accionar represivo un grupo de personas de trayectorias militantes diversas constituyeron en Neuquén una filial de la Asamblea Permanente por los Derechos Humanos (APDH) a mediados del año $1976^{3}$. Comparado con lo que sucedía en otras regiones de la Argentina, la respuesta neuquina fue precoz y bien organizada. Esto fue posible gracias al soporte institucional de la Iglesia Católica local. Si bien en otras ciudades hubo sacerdotes que abrieron sus parroquias a las madres y los familiares, siendo la iglesia de la Santa Cruz uno de los casos emblemáticos, lo distintivo en el catolicismo

1 Sobre los cambios y continuidades en materia represiva en el período 1973-1983 véase Gabriela Águila; Santiago Garaño y Pablo Scatiza (coord). Represión estatal y violencia paraestatal en la historia reciente argentina: Nuevos abordajes a 40 años del golpe de Estado, La Plata, UNLP, 2016

2 Como parte de este despliegue realizaron sistemáticas tareas de inteligencia; establecieron tres centros clandestinos de detención que funcionaron hasta 1978 y lugares de alojamiento de detenidos políticos (como la Unidad 9 del Servicio Penitenciario Federal); desplegaron amplios operativos represivos. Todo ello tuvo como resultado más de 30 personas desaparecidas y más de 120 casos denunciados ante la justicia de secuestros y torturas bajo el régimen militar. Pablo Scatizza, Un Comabue violento. Dictadura, represión y juicios en la Norpatagonia argentina, Buenos Aires, Prometeo, 2016.

${ }_{3}^{2}$ La APDH Nacional se había creado en Buenos Aires el 18 de diciembre de 1975. Única en su variedad política, ideológica y sectorial, el consejo de presidencia al que pertenecía el obispo de Neuquén, Jaime de Nevares, estaba conformado por más de 130 miembros de las expresiones políticas y sectoriales más variadas. 
neuquino fue que actuó como fuente, facilitador y potenciador del movimiento de derechos humanos a nivel local prestándole sus estructuras de organización y comunicación, dinero, personal u organizaciones mediadoras que comunican habilidades, tácticas y visiones 4 .

No obstante, la sociedad neuquina fue poco permeable al discurso y el accionar de la APDH. A pesar de contar con la legitimidad aportada por el aval del obispo católico, Jaime de Nevares, el crecimiento de la filial tuvo varios obstáculos. Además de las dificultades impuestas por el accionar del terrorismo de Estado que afectaban a todo el entramado social, la organización tuvo que lidiar con factores locales que desactivaron la participación. La existencia de un imaginario -heredado de la etapa territoriana- en el que los militares eran asociados a la provisión de servicios para la vida cotidiana, el progreso de la ciudad y de la provincia; la presencia de un entramado de relaciones cívico-militares que hacía que los oficiales y suboficiales (y sus familias) fueran considerados vecinos y amigos; la ausencia de acciones armadas en la región en los años previos a la dictadura conjugado con la poca cantidad y visibilidad de esas acciones en dictadura y la escasez de operativos de secuestro en la vía pública que ayudaron a construir la idea de que en "Neuquén no pasaba nada"; y, finalmente, la buena performance económica de la provincia en esos años. En esa coyuntura, cuando la APDH local comenzó a denunciar las violaciones y, posteriormente, a identificar al régimen militar como responsable de las mismas, su mensaje fue fuertemente resistido; el mismo sonaba inverosímil para la mayoría de los miembros de una sociedad en la que los militares eran "los amigos y vecinos" y cuya prospera cotidianeidad no había sido alterada por haber presenciado o vivido de cerca las actividades represivas del Estado ${ }^{5}$.

Compuesta por un núcleo fundador al que se le sumaron progresivamente algunos familiares de detenidos y desaparecidos, la filial local contó, casi desde sus inicios, con la presencia de algunos jóvenes. Este acompañamiento cristalizó hacia 1980 en la conformación del "Seminario Juvenil" de la APDH en donde ellos ocuparon un rol protagónico. Con la creación de esta nueva instancia la organización interpelaba a los jóvenes ofreciéndoles "una tribuna en la que su voz no iba a ser acallada y un lugar en la lucha por la plena vigencia de los derechos humanos".

Basado en el entrecruzamiento de fuentes orales y documentales ${ }^{6}$, este artículo reconstruye la creación del "Seminario Juvenil" de la APDH en Neuquén y analiza su rol en la formación de los jóvenes en una coyuntura histórica específica, 1980-1981, antes del retorno masivo al espacio público posterior a la guerra de Malvinas en 19827. Asimismo, indaga sobre el impacto que la pertenencia a esta organización tuvo en la trayectoria de aquellos jóvenes, considerando el cruce entre sus historias de vida, la vigencia del contexto represivo, el perfil político-ideológico de la organización y el riesgo que asumían al participar de la misma.

\footnotetext{
${ }^{4}$ María Cecilia Azconegui, "La Iglesia Católica y la APDH neuquinas frente al terrorismo de Estado”, Muñoz Villagrán, Jorge (coord.), Pedagogía política en Don Jaime de Nevares, Neuquén, Universidad Nacional del Comahue, 2012, pp. 256-288. Joaquín Perrén, "Erase una vez en la Patagonia - Luces y sombras de la economía neuquina (1958-1991)", Observatorio de la Economía de la Patagonia, 2007,Disponible en internet http://www.eumed.net/oe-pat/.

5 María Cecilia Azconegui, "Desobediencia debida. La defensa de los derechos humanos en el Alto Valle y Neuquén, 19761983”, Rubén Kotler (comp.), En el país del sí me acuerdo. Los orígenes nacionales y transnacionales del movimiento de derechos bumanos en Argentina: De la dictadura a la transición, Buenos Aires, Imago Mundi, 2014, pp. 47-77.

${ }^{6}$ Se realizaron entrevistas semi-estructuradas con cuatro de las siete personas que formaron parte de esta primera etapa del "Seminario Juvenil". Los nombres han sido cambiados para preservar la identidad de los entrevistados. Por otra parte, los documentos analizados pertenecen a los archivos de la APDH central y de la filial Neuquén y Alto Valle.

7 "Juventud" es una categoría nativa que aparece en las fuentes documentales y testimoniales. Los protagonistas la utilizan para referenciarse y denominar a sus pares a los que invitaban a participar del Seminario. Los jóvenes que participaban de la experiencia aquí analizada representan una de las múltiples formas de ser jóvenes que coexistieron en Neuquén a partir de 1980. Éste es el sentido con el que utilizo el término en este trabajo. No obstante, es preciso señalar que la mayoría de los estudios en juventudes coinciden en que la juventud es una construcción histórica, social y cultural, y que la definición de esa condición ha sido una forma de imponer límites y de producir un orden en el que cada quien debe ocupar su lugar. Pierre, Bourdieu, Sociología y cultura. México: Grijalbo, 1978; Mariana Chaves (coord), Estudios sobre juventudes en Argentina 1. Hacia un estado de la cuestión, La Plata, Red de Investigadora/es en Juventudes Argentina y Editorial de la UNLP, 2009.
} 
El rol de la APDH en la formación de los jóvenes durante la dictadura es una problemática prácticamente soslayada por la historiografía. Desde las primeras investigaciones la organización fue analizada como parte de un sujeto social más amplio, un movimiento social, el movimiento de derechos humanos $(\mathrm{MDH})^{8}$. Estos primeros estudios conformaron una "narrativa clásica" en la que las distintas organizaciones fueron caracterizadas por su composición, sus estrategias, sus discursos, y diferenciadas en función de sus lineamientos frente al poder'. En esa coyuntura la APDH, una de las entidades menos estudiadas, fue caracterizada como un organismo de "no afectados" (en oposición a los "de afectados" conformados principalmente por madres y familiares en general), de amplia pluralidad en términos políticos, ideológicos y religiosos, especializado en la recepción de denuncias y la presentación de habeas corpus colectivos, y por tener una actitud moderada y cautelosa frente al poder. La pregunta por el impacto del $\mathrm{MDH}$ en la cultura política estuvo presente en estos trabajos pioneros que destacaron su rol en la generación de prácticas políticas innovadoras, la instalación de los derechos humanos como un patrimonio, la formación de un nuevo imaginario republicano y la revalorización de la democracia en las fuerzas políticas y sociales en el contexto de la transición ${ }^{10}$. Las recientes investigaciones que retomaron este interrogante confirmaron el rol del $\mathrm{MDH}$ en la renovación de la cultura política argentina, siendo clave en la constitución de los derechos humanos como una "verdad evidente"11. No obstante, también han complejizado e historizado el proceso de apropiación de la narrativa de los derechos humanos por parte de las fuerzas políticas y sociales estableciendo que el mismo no se produjo inmediatamente después de la derrota en la Guerra de Malvinas sino una vez avanzado el proceso de la transición ${ }^{12}$.

Paralelamente, nuevas pesquisas han complejizado la "narrativa clásica" que se había proyectado como la "historia nacional" aun cuando había sido construida a partir del análisis de la dinámica del MDH en la zona de Buenos Aires y localidades cercanas como La Plata. Estos análisis, que hicieron de la reducción de escala una opción metodológica, han permitido profundizar en la especificidad de las experiencias históricas según las diversas latitudes identificando nuevas organizaciones y la presencia de dinámicas y temporalidades disímiles ${ }^{13}$. En línea con estos trabajos, ese artículo recupera la discusión general sobre el $\mathrm{MDH}$ y la cultura política analizada a escala nacional pero desde una perspectiva diferente con foco en el análisis situado del "Seminario Juvenil" de la APDH que actuó en Neuquén desde 1980 para reflexionar sobre los valores, las prácticas políticas y el ideario asociadas a una de sus organizaciones, su rol en la formación de los jóvenes que la integraron y el impacto que la pertenencia a la misma tuvo en la formación de los militantes.

\footnotetext{
${ }^{8}$ Entre otros, Héctor Leis, El movimiento por los derechos humanos y la politica Argentina, Buenos Aires, CEAL. 1989; Elizabeth Jelin, "La política de la memoria: el movimiento de derechos humanos y la construcción democrática en la Argentina", Carlos Acuña et al., Juicio, castigos y memorias. Derechos bumanos y justicia en la política argentina, Buenos Aires, Nueva Visión, 1995, pp. 101-146.

9 Luciano Alonso, "Terror de Estado y luchas pro derechos humanos en Argentina: las dimensiones ocluidas", Ayer, Asociación de Historia Contemporánea, N 107, 2017, pp. 99-124.

10 Jelin, op. Cit; Daniel García Delgado, "Nuevos patrones de participación política en procesos de transición a la democracia: el caso argentino”, Oscar Oszlak (comp.), Proceso', crisis y transición democrática, Buenos Aires, CEAL, 1984; Inés González Bombal y María Sondereguer, "Derechos humanos y democracia", Elizabeth Jelín (comp.), Movimientos Sociales y Democracia emergente, Buenos Aires, CEAL, 1987, pp. 85-112; Oscar Landi e Inés González Bombal, "Los derechos en la cultura política", Carlos Acuña et. al., Juicio, castigos y memorias. Derechos humanos y justicia en la política argentina, Buenos Aires, Nueva Visión, 1995, pp. 147192.

11 Emilio Crenzel, “Los derechos humanos, una verdad evidente de la democracia en la Argentina”, Estudios, N²9, 2013, pp. 73-91.

12 Marina Franco, El final del silencio. Dictadura, sociedad y derechos bumanos en la transición (Argentina, 1979-1983), Buenos Aires, FCE, 2018.

13 Silvina Oviedo y Ana Carol Solis, Violencia institucionalizada y formas de resistencia social: Los organismos de Derechos Humanos en Córdoba durante la dictadura, Tesis de Licenciatura en Historia, UNC, Inédito. 2006; Luciano Alonso, Luchas en plazas vacías de sueños. Movimiento de derechos humanos, orden local y acción antisistémica en Santa Fe, Prohistoria Ediciones, Rosario, 2011; Rubén Kotler, Huellas de la memoria en la resistencia antibussista. Historia del movimiento de derechos bumanos en Tucumán 1976-1999, Imago Mundi, Buenos Aires, 2018; Marianlea Scocco, La conformación del movimiento de derechos humanos de Rosario (1970-1985), Tesis doctoral en Historia, UNR, mimeo. 2018.
} 
Por otra parte, este artículo entra en diálogo con la reciente investigación de Laura Luciani sobre las representaciones, políticas y experiencias juveniles en Rosario durante la última dictadura militar ${ }^{14}$. La historiadora visibiliza que los jóvenes fueron sujeto no sólo de represión sino también de producción de las políticas de la última dictadura militar que veía en ellos a los "herederos del proceso". Sus reflexiones sobre los modos en que los miembros de las sucesivas Juntas se refirieron a los jóvenes y las políticas que implementaron para desarrollar sus objetivos es una referencia ineludible para este trabajo ya que la convocatoria de la APDH no estuvo aislada. Convivió y confrontó con otros llamamientos similares que, proviniendo de otros posicionamientos político-ideológicos, también proyectaban sobre el rol de los jóvenes en el futuro de la vida nacional. En particular, el elaborado por los dirigentes castrenses (y sus aliados civiles) que, habiendo vencido en el plano armado, mantenían su preocupación por la inconclusa batalla cultural que tenía por trofeo a las mentes, espíritus y corazones de los argentinos.

La evolución de la APDH local como organismo perteneciente al MDH es analizada teniendo en consideración la articulación entre tres grupos de factores: la estructura de las oportunidades políticas, las formas de organización a disposición de los contestatarios, y los procesos colectivos de interpretación, atribución y construcción social que median entre la oportunidad y la acción ${ }^{15}$. Es decir, se parte de la idea de que los elementos dinámicos del contexto adquieren importancia siempre y cuando los actores logren interpretarlos como una oportunidad para participar y tengan los recursos necesarios para actuar en consecuencia. Asimismo, la participación en el "Seminario Juvenil" es entendida como una militancia de "alto riesgo" ya que quienes participaron de esta instancia durante la última dictadura militar se exponían a la posibilidad de sufrir represalias ya sean legales, sociales, físicas, etc. por participar de las actividades de la organización ${ }^{16}$. Aunque sólo uno de los miembros del grupo fundador del "Seminario Juvenil" de la APDH local tenía alguna experiencia de activismo previa (una de las características de este tipo de activismo para Mc Adam) considero que su categoría es de utilidad porque focaliza en tres rasgos claves para reflexionar sobre la experiencia y trayectoria de quienes participaron en la APDH en el marco de la dictadura: el profundo compromiso con la ideología y los objetivos de la organización, la integración en redes de activismos (en este caso las del catolicismo) y la relativa libertad de restricciones personales que podrían haber aumentado el peligro de la participación (la disponibilidad biográfica de los militantes).

\section{El contexto político local}

La movilización, así como la participación social y política experimentaron un profundo cambio en el marco de la crisis y descomposición interna del régimen peronista. Ante el avance de la represión estatal y la violencia paraestatal, los altos niveles de los primeros meses comenzaron a disminuir para reducirse a la mínima expresión en el contexto dictatorial caracterizado por una extendida desmovilización de la sociedad. La normativa del régimen militar instaurado con el golpe de estado del 24 de marzo de 1976 trajo aparejada una nueva redefinición en la dinámica social y política. Las reglas del juego -delineadas con antelación- fueron marcadas desde el comienzo con la aplicación de medidas clásicas en el repertorio de las dictaduras y la utilización de los dispositivos represivos específicos del terrorismo de Estado. Es decir, a la permanencia del estado de sitio -decretado el 6 de noviembre de 1974- se sumaron la disolución del congreso, la intervención de la CGT y de los gremios más poderosos,

\footnotetext{
14 Laura Luciani, Juventud en dictadura: representaciones políticas, experiencias juveniles e Rosario (1976-1983), La Plata, Posadas, Los Polvorines, UNLP-UNS;-UNGS, 2017.

15 Doug Mc Adam, John Mc Carthy y Mayer Zald (comp.) Movimientos Sociales: perspectivas comparadas, Madrid, Istmo, 1999 , p. 22. 16 Mc Adam ha señalada que el nivel de costo y de riesgo asociado a la acción colectiva tiene incidencia en el proceso de reclutamiento de los participantes, así como también en el impacto que la experiencia tiene en la trayectoria del militante. Doug McAdam, “The Biographical Consequences of Activism”, American Sociological Review, 1989, 54, pp. 744-760.
} 
la suspensión y prohibición del accionar de los partidos políticos ${ }^{17}$, la conculcación de derechos civiles que -como la libertad de expresión y de asociación- permitían ejercer la política y, finalmente, la represión y la utilización del terror estatal. El accionar conjunto de estas políticas gubernamentales implicó que las restricciones a la participación fueran reforzadas por la inducción de determinadas conductas -guardar silencio, no denunciar, no expresar oposición, entre otras- y que se instalara, junto a la coerción arbitraria y rigurosa, una "cultura de miedo", no sólo producto del autoritarismo, sino, simultáneamente, condición de su perpetuación, que favorecía la pasividad y la uniformidad ${ }^{18}$.

A pesar del terror sembrado por el Estado y el rol ejercido por el miedo en la determinación de las conductas, la sociedad no fue totalmente dominada o paralizada. Si bien se produjo una privatización de la sociedad y de la política -es decir, que la política se redujo a decisiones unilaterales desde el Estado mientras que la mayoría de sus destinatarios, los ciudadanos, debieron confinarse a la vida privada-, este proceso no implicó su desaparición sino la transformación de su práctica y el surgimiento de nuevos patrones de participación ${ }^{19}$. En lo que respecta a los actores tradicionales, los partidos políticos siguieron activos en la clandestinidad y sus dirigentes intervinieron por medio de declaraciones a título personal sobre ciertos temas -excepto asuntos sensibles como la "lucha contra la subversión" y los desaparecidos. En Neuquén fue notable la influencia del partido provincial (el Movimiento Popular Neuquino) y de sus máximos líderes en las políticas económicas del período y en la participación pautada desde la cúpula gubernamental ${ }^{20}$. Las nuevas modalidades de participación, por su parte, estuvieron intrínsecamente relacionadas con las características del proceso político en curso ya sea porque procedían desde el mismo Estado o porque se desarrollaron como reacción a políticas específicas.

Si focalizamos en los discursos y las acciones del Estado, es posible ver que el gobierno hacía política pero no asumía su actividad como tal, propiciando su despolitización ${ }^{21}$. La política, sin ciudadanos ni partidos, pasó a expresarse en categorías económicas organizadas en torno a un discurso técniconeutral que ocultaba que "el modelo económico era más 'política' que 'economía"' y los argentinos dejaron de ser interpelados como sujetos políticos para ser convocados al espacio público en calidad de consumidores, siendo el mercado el lugar en el cual se configuraban las nuevas identidades ${ }^{22}$. De esta manera, la política represiva y las fuerzas del mercado conspiraron de manera conjunta para transformar a las personas en consumidores preocupados por la maximización en vez de ciudadanos responsables y comprometidos. En definitiva, la redefinición de los sujetos formaba parte del proyecto refundacional liderado por las FFAA que consistía en crear un nuevo orden a partir de la reorganización del conjunto de la sociedad, y la reestructuración y recomposición de las bases del capitalismo nacional; inaugurar un "nuevo ciclo histórico" que clausurara la persistente alternancia entre gobiernos civiles y militares ${ }^{23}$.

Sin embargo, los discursos y acciones estatales no sólo generaron usuarios pasivos e individualistas. Ellos también provocaron el surgimiento de formas alternativas de participación que emanaron de nuevos

\footnotetext{
${ }^{17}$ La distinción entre partidos políticos prohibidos y suspendidos era central para los sectores del régimen que creían que la actividad política no podía ser erradicada totalmente de la sociedad y pretendían conformar una sociedad política reducida y controlada desde el Estado. Los partidos suspendidos - entre los que se encontraba el Movimiento Popular Neuquino- aportaron los dirigentes partidarios que permitieron cubrir cargos de intendentes municipales y de embajadores para obtener legitimidad internacional. María de los Ángeles Yannuzzi, Politica y Dictadura. Los partidos politicos y el Proceso de Reorganización Nacional', 1976 1982, Rosario, Editorial Fundación Ross, 1996.

18 García Delgado, op. Cit.; Yannuzzi, op. Cit.

19 García Delgado, op. Cit, Yannuzzi, op. Cit.

${ }^{20}$ La gestión de Felipe Sapag como interventor provincial (1970-1972) luego de los conflictos sociales de los años 1969/70, fue un antecedente para que en 1976 el nombre del líder emepenista estuviera en la lista de los posibles políticos a mantener en sus cargos y para que el partido (el MPN) fuera considerado en los planes políticos de los sectores "politicistas".

21 Norberto Lechner "¿Qué significa hacer política?”, Documento de Trabajo, FLACSO, 1982.

22 Lechner, op. Cit, Yannuzzi, op. Cit.

23 Paula Canelo, La política secreta de la última dictadura militar argentina, Buenos Aires, Edhasa, 2016.
} 
actores sociales -como las organizaciones defensoras de los derechos humanos- que recurrieron a canales en directa relación con el tipo de autoritarismo implementado.

Paralelamente, la falta de referentes colectivos y la situación de anomia que las personas experimentaban gestaron el clima propicio para el auge de las comunidades religiosas ${ }^{24}$. El estrecho vínculo político-ideológico entre las jerarquías militar y eclesiástica posicionó al catolicismo en un lugar potencialmente estratégico aunque no siempre fuera capitalizado ${ }^{25}$. En este marco, miembros de la comunidad católica neuquina propiciaron el surgimiento de los nuevos actores como la APDH y favorecieron su acción política ${ }^{26}$. Al igual que sus pares en otros espacios, estas organizaciones, basadas en una reivindicación ética y una fuerte desafección sobre el poder estatal, implementaron nuevas formas de lucha en donde primó la no violencia, la movilización en el espacio público -que en Neuquén estuvo primero asociada a las manifestaciones religiosas y recién en 1980 cobraron autonomía - y la articulación internacional.

No obstante la validez de esta caracterización general, para analizar la dinámica social y política es necesario incorporar los matices de cada una de las etapas del régimen. La coyuntura de los años 1980 y 1981, que enmarcó la creación del "Seminario Juvenil" en Neuquén, registró algunas particularidades relacionadas tanto con los diversos proyectos existentes dentro de las FFAA (politicistas vs corporativistas) como con la performance del gobierno (crisis económica y de legitimidad) ${ }^{27}$. El intento de apertura política de Viola implicó el reconocimiento explícito de la actividad política y cierta liberalización en su práctica ${ }^{28}$. Por ejemplo, se crearon en Neuquén instancias de discusión y organización como la Multisectorial y la Multipartidaria; y se concretaron las primeras movilizaciones de la APDH local en el espacio público. Sin embargo, la propuesta de Viola que contaba con escasos apoyos en las FFAA tampoco logró despertar interés en las organizaciones que se proponía interpelar ${ }^{29}$. Si bien permitió cierto nivel de liberalización, éste no redundó en su beneficio. La creación de la Multipartidaria por los partidos políticos, la segunda huelga general de los sindicatos más combativos y el documento "Iglesia y Comunidad Nacional" -en donde el episcopado argentino se desvinculó públicamente del régimen militar- reflejan no sólo la incapacidad de Viola para sumar voluntades sino también cambios en la dinámica social y política, y el reposicionamiento de los actores.

En suma, la debilidad de Viola y el cuestionamiento público de sus adversarios militares restaron impacto y viabilidad al intento de liberalización manteniéndose la represión, la intimidación, la persecución, la incertidumbre, el miedo, la ilegalidad y la clandestinidad como las variables centrales que enmarcaban y condicionaban la práctica política. Aunque al igual que en otras regiones del país la intensidad de la acción represiva del Estado, disminuyó a partir de 1979, el hostigamiento y la persecución a la población civil continuaron ${ }^{30}$. Como parte de la intimidación general desplegada en Neuquén hacia la APDH hubo hechos concretos durante 1981 como el atentado con gamexane en la catedral (cuando

${ }^{24}$ Lechner, op. Cit.

${ }^{25}$ La Iglesia Católica Argentina es una institución muy heterogénea atravesada por divisiones internas. Así, mientras que algunos sectores de la Iglesia Católica sufrieron la represión dentro de sus filas -contando con detenidos, desaparecidos y asesinados-, otros legitimaron al régimen. Véase entre otros, Soledad Catoggio, Los desaparecidos de la Iglesia. El clero contestatario frente a la Iglesia, Siglo XXI, 2016. Paralelamente, como esta institución fue una fuente de legitimación central para la dictadura, los miembros de su jerarquía gozaron de márgenes de acción inusitados al igual que las prácticas católicas por ellos promocionadas. Como señala Lida las peregrinaciones católicas constituyeron uno de los pocos espacios en donde la sociabilidad joven era aceptada pública y masivamente, y donde "las masas se habrían sentido por completo seguras". Miranda Lida, "Las masas católicas en los años de la dictadura, 1976-1982", Entrepasados, 2008, 34, pp. 55-73.

${ }^{26}$ María Cecilia Azconegui, op. Cit.

27 Viola retomó la iniciativa de diálogo anunciada por Videla y la profundizó. El giro político de Viola se sustentó en dos planos: en la necesidad de recuperar la legitimidad pérdida mediante la gestación de nuevas alianzas y en su propia convicción acerca de las bondades de la apertura. Véase Canelo, op. Cit.

28 Canelo, op. Cit; Yannuzzi, op. Cit.

${ }^{29}$ Canelo, op. Cit.

${ }^{30}$ Scatizza, op. Cit. 
se celebraba una misa-acto de denuncia en el día de las madres) o la balacera a la puerta de acceso a las oficinas del obispado donde se realizaban las reuniones de la organización ${ }^{31}$.

\section{El funcionamiento del "Seminario juvenil" en Neuquén}

La sede de la APDH estaba en la ciudad de Neuquén (capital de la provincia homónima) y allí se realizaron las actividades organizadas por la entidad. No obstante, la filial adoptó el nombre Neuquén y Alto Valle porque estuvo conformada no sólo por residentes de la capital provincial sino también por personas que vivían en otras ciudades neuquinas y localidades cercanas de la zona del Alto Valle de Río Negro como Cipolletti, Allen y Roca.

Desde los primeros años un pequeño grupo de jóvenes -unos seis o siete en total- formaba parte de las reuniones de la APDH los martes a la noche en las instalaciones del obispado neuquino. A pesar de no ser familiares de represaliados, ni haber sido convocados por el núcleo fundador, su llegada había sido posible gracias a la red de relaciones en las que estaban insertos la cual les había permitido enterarse de la existencia de la organización -que operaba en la semiclandestinidad- y ser aceptados por quienes la integraban ${ }^{32}$.

El grado de involucramiento de los jóvenes fue creciendo progresivamente 33 . Si bien su presencia podía llegar a generar un compromiso y una responsabilidad extra para el resto de los integrantes -los adultos asumían su cuidado y protección garantizando, entre otras cosas, que todos llegaran a sus casas a salvo después de las reuniones y actividades- ellos participaban activamente de las acciones del grupo. Uno de los actos más significativos fue la primera manifestación pública de la APDH, el 14 de agosto de 1980, en la que sus miembros se plantaron en la plaza frente a la gobernación con un cartel demandando justicia ${ }^{34}$.

La estrategia fue ir juntándonos de a poco, para no llamar la atención y porque las manifestaciones estaban prohibidas. Algunos comenzaron a caminar desde el monumento, por la calle. En las esquinas iba apareciendo el resto. Vinieron familiares de Cutral Co y Plaza Huincul [ciudades neuquinas] (...) Nos generó mucho miedo porque los que habían entrado a dejar el petitorio no volvían. Salieron como una hora después... ${ }^{35}$.

El armado de esa manifestación fue una de llamar por teléfono, de avisar la hora de estar todos dispersos por la plaza y a la hora tal irnos acercando y un determinado momento desplegar el cartel y cantar el himno y se armó un despelote... (...) se garantizó una cantidad mínima de gente y algunos llegamos a dejar cartas. Yo, por ejemplo, a mis viejos no les avise. Sí a mi hermano, y dejé por lo menos tres cartas de lo que había que hacer por las dudas, porque era necesario ${ }^{36}$.

Si el anuncio de la liberalización política fue interpretado como un cambio en la estructura de las oportunidades políticas que habilitó la posibilidad de salir a la calle por primera vez, los testimonios

\footnotetext{
31 Azconegui, op. Cit.

32 Sobre la dinámica de reclutamiento que utilizó la organización consultar Azconegui, op. Cit.

33 Las actividades consideradas "más riesgosas" quedaban reservadas a los adultos. Por ejemplo, los jóvenes no firmaban los documentos que la organización presentaba ante las autoridades ni formaban parte de la comitiva cuando miembros de la filial concurrían al comando de la Sexta División del Ejército (radicado en Neuquén) a requerir información sobre personas detenidasdesaparecidas.

34 Esa primera manifestación pública que incluyó la entrega de un petitorio al gobernador militar (en esa oportunidad entraron a la gobernación Noemí Labrune y Horacio Ventura por la APDH y Oscar Ragni y Lolín Rigoni por Familiares) se realizó en coordinación con los organismos defensores de los derechos humanos de Buenos Aires quienes ese día se manifestaron en la Plaza de Mayo.

35 Susana, Entrevista realizada por la autora. Neuquén, 29 de mayo de 2009.

${ }^{36}$ Juana, Entrevista realizada por la autora, Neuquén, 30 de julio de 2008.
} 
reflejan que la realización del plantón no estuvo exenta de temor. La dictadura enviaba señales poco claras. Si, por un lado, liberaba a cientos de presos políticos, por el otro, también detenía a líderes reconocidos de la APDH central como Emilio Mignone y Augusto Conte McDowell cuando realizaban manifestaciones públicas. Asimismo, el suicidio de algunos detenidos era un índice revelador de la continuidad de un sistema carcelario diseñado para aniquilar y destruir como denunciaba la APDH. Entonces, el riesgo que asumían al salir a la calle no era abstracto sino bien concreto. Sabían de las desapariciones (quizás no de su envergadura y sistematicidad pero sí de su existencia), de las malas condiciones de detención, de los suicidios y que hasta las personalidades destacadas eran tocadas. Los relatos sobre lo ocurrido aquel día ponen en un primer plano el contexto represivo imperante y, en consecuencia, el riesgo que los jóvenes corrían y el miedo que sentían quienes decidían pasar a la acción ${ }^{37}$. Pero también, muestran las estrategias desarrolladas para contrarrestar la represión estatal y la incertidumbre con respecto a las repercusiones de la manifestación. Así, la decisión de converger en la plaza de manera atomizada para evitar que las fuerzas de seguridad desactivaran la movilización antes de que la misma se concretara y la escritura de cartas con directivas en caso de no volver después de la acción pública dan cuenta de la experiencia adquirida por la organización y por estos jóvenes en una militancia clandestina y de alto riesgo que les enseñaba saberes específicos.

Por otra parte, la importancia numérica de los jóvenes -constituían la tercera parte de los presentes ese día-, demuestra el destacado rol que los mismos desempeñaban en la organización. Su creciente protagonismo cristalizó a mediados de 1980 en la constitución del "Seminario Juvenil" permitiendo una mayor inserción de la APDH y su discurso en este sector de la sociedad ${ }^{38}$. Esta iniciativa fue producto de la conjunción de una serie de factores: los cambios en la coyuntura política, una lectura de los mismos que entendía que era el momento de salir a la calle e incorporar más personas, la maduración interna del grupo (para 1980 la delegación ya tenía cuatro años de experiencia) y las vinculaciones con los jóvenes de la APDH central. De hecho, la concreción se realizó después de la visita a Neuquén de uno de los dirigentes del Seminario de Buenos Aires y la concurrencia de varios jóvenes neuquinos a la reunión de clausura de la II sesión del Seminario de la APDH a nivel nacional ${ }^{39}$.

A partir de allí, los jóvenes -que siguieron trabajando con y acompañando a los adultos en la APDH- tuvieron sus reuniones en las que organizaban y planificaban las actividades que llevaban adelante, publicaron algunos números de su propio boletín, y viajaron a Buenos Aires con cierta periodicidad para coordinar con los jóvenes de otras ciudades. Para cumplir con sus objetivos se dividieron en tres comisiones (laborales, docentes y universitarios), relacionadas con la formación y los espacios de inserción de los integrantes, en las que se abocaban a las tareas de investigar, reflexionar y difundir la grave situación de vulnerabilidad de los derechos humanos en los jóvenes universitarios y trabajadores ${ }^{40}$. La dinámica de trabajo implicaba cierto nivel de autonomía con respecto a los adultos

${ }^{37}$ El contexto de vigilancia en que se realizó el plantón quedó reflejado en la nota del diario local. Según la crónica del Río Negro, "la manifestación pública alteró el ritmo normal de ese sector de la ciudad. Transeúntes y automovilistas se detuvieron para leer el cartel y algunos funcionarios públicos, entre ellos el secretario general de la gobernación, salieron para informarse de lo que estaba sucediendo". En coincidencia con los testimonios, el diario informaba que los cuatro representantes demoraron dos horas en salir y que, en ese lapso de tiempo, los manifestantes fueron fotografiados de todos los ángulos por fotógrafos que no pertenecían a ningún medio de difusión y, posteriormente, rodeados por personal de la policía, uniformados y de civil, que les pidieron los documentos y llenaron fichas con sus datos. Río Negro, "Presentación de familiares de personas desaparecidas, Río Negro, General Roca, 1980, p. 13.

38 APDH, Informe de la delegación Alto Valle y Neuquén, 8 de agosto, 1980.

39 APDH, Resumen del encuentro de delegaciones, 18 de septiembre de 1981. La creación del Seminario Juvenil replicó la experiencia que se desarrollaba desde 1979 en la APDH central de Buenos Aires y que lentamente se fue extendiendo a las distintas delegaciones del país. La ausencia de investigaciones sobre el Seminario Juvenil en Buenos Aires o en cualquiera de las distintas delegaciones en la que se reprodujo la experiencia impide, por el momento, establecer comparaciones.

$40 \mathrm{El}$ punto de partida de las investigaciones y de las actividades que aparecen en los boletines locales parece haber estado muy vinculado a las reuniones nacionales que se realizaban en Buenos Aires. Así, después de la reunión nacional sobre "derechos laborales y juventud" apareció un informe sobre la vigencia de los derechos humanos de los jóvenes en materia laboral. De 
pero, como recuerda Juana, "las actividades estaban avaladas por los grandes, separadas, pero no totalmente". Así, si bien los jóvenes conformaron su propio espacio, lo hicieron en el seno de la APDH siguiendo sus objetivos y lineamientos generales. De este modo, los boletines del "Seminario Juvenil" reflejaban la perspectiva de los jóvenes y de los adultos de la APDH con respecto a la juventud, o al menos el consenso al cual arribaron en el momento de la publicación ${ }^{41}$.

Los boletines del "Seminario Juvenil" cumplían con la función de difundir las investigaciones del grupo y las actividades que realizaban, pero también servían como una carta de invitación para que los jóvenes se fueran acercando a las actividades (aparecían tanto las actividades pasadas como las que pretendían realizar). La leyenda de las portadas de 1981 era clara al momento de definir los objetivos de las acciones y lo que se esperaba de aquellos que quisieran sumarse a la iniciativa.

\section{LA GRAN TAREA DE NUESTRO TIEMPO}

- Despertar: una viva conciencia de justicia.

- Defender: los derechos de los pobres y oprimidos.

- Denunciar: los abusos como consecuencia de las desigualdades entre poderosos y débiles.

- Buscar: la justicia exigiendo la verdad.

La inscripción condensa un conjunto de elementos. En principio es posible identificar una lectura de la coyuntura, "nuestro tiempo", como una instancia en la cual se había acabado la espera y era necesario pasar a la acción. A partir de ese diagnóstico inicial, el grupo realizaba su presentación y convocatoria $-\mathrm{a}$ aquellos jóvenes que se sintieran identificados con su perspectiva- estableciendo su posicionamiento y accionar frente a la realidad y a las actitudes y comportamientos existentes frente a ella. Así, junto al objetivo explícito de convertirse en el vehículo para "despertar una viva conciencia de justicia" es posible leer una denuncia a la pasividad imperante en amplios sectores de la sociedad frente a las injusticias del régimen militar. De manera similar, la necesidad declarada de "defender los derechos de los pobres y oprimidos" y "denunciar los abusos como consecuencia de las desigualdades entre poderosos y débiles" permite vislumbrar una crítica hacia las políticas de un gobierno que no sólo generaba pobres y oprimidos, sino que también los colocaba en una situación de gran vulnerabilidad e indefensión. Asimismo, en la meta de "buscar la justicia exigiendo la verdad" es posible distinguir el reclamo específico por la violación a los derechos humanos en una coyuntura en la que esta problemática era uno de los temas a definir en el proyecto politicista de Viola y los partidos políticos aún no se habían pronunciado al respecto. Finalmente, la mirada general sobre el joven que se anunciaba en la portada se plasmaba en hechos concretos en el interior del boletín con los informes de las comisiones en donde se podía apreciar la actitud reflexiva y crítica de los jóvenes y la reseña de las actividades realizadas.

Resumidamente, las acciones de alto riesgo en las que los jóvenes participaron activamente, el proceso de autonomía iniciado con la conformación del "Seminario Juvenil" y las actividades realizadas en ese marco, así como el posicionamiento frente al gobierno y la sociedad reflejado en los boletines de 1981 denotan que la APDH situada en Neuquén permitía un rol activo y protagónico del joven en la

manera similar, luego de realizada la IV Jornada Nacional sobre Educación y Cultura, se publicó un informe sobre la situación actual de la educación y los derechos de enseñar y aprender, y se realizó en Neuquén una actividad con Alfredo Bravo (docente y líder sindical integrante de la APDH central) en la que se discutió sobre "la identidad cultural, el espíritu crítico y los derechos humanos". Aunque el grupo orgánico era reducido, a fines de 1981 las actividades del Seminario congregaban a unos 500 jóvenes en una ciudad que tenía 90.000 habitantes según el censo de 1980. APDH, op. Cit.; APDH Neuquén y Alto Valle, Subcomisión Seminario Juvenil. Delegación Alto V alle, mayo y agosto de 1981.

${ }^{41}$ El Boletín del "Seminario Juvenil" fue una experiencia muy corta que tuvo escasos números y circuló entre la red de relaciones de los integrantes. 
sociedad de cara a modificar su presente y construir su futuro. Si bien los adultos cuidaban, protegían, monitoreaban, a los jóvenes y sus actividades también los avalaban. Las iniciativas partían de las inquietudes que ellos planteaban ya fuera a partir de su propia realidad o de los intercambios que realizaban con sus pares de otros lugares en los encuentros nacionales a los que concurrían en la ciudad de Buenos Aires. Este rol activo y creativo de los jóvenes en el seno de la APDH presenta rasgos que permiten inferir los gérmenes de una nueva manera de pensar y de ejercer la participación (y al ciudadano) -alejada tanto de la tradición liberal (de corte electoralista) como peronista (de carácter movilizante) que contenían elementos restrictivos en cuanto apuntaban a una participación más vinculada con la decisión entre opciones dadas que a la elaboración de las mismas ${ }^{42}$. Por otra parte, esta concepción de la juventud y de su rol en la sociedad planteaba significativas diferencias con otros discursos de la época con los cuales convivía en el espacio público.

En lo que respecta a las cúpulas militares, los jóvenes eran una pieza central del proyecto de "reorganización nacional" ya que estaban llamados a ser los "herederos del proceso". Si, como planteamos al principio, la política gubernamental con respecto a la sociedad tuvo el doble propósito de erradicar los comportamiento sociales y políticos considerados peligrosos -lo que incluyó en su práctica más extrema la eliminación de aquellas personas consideradas irrecuperables- y, al mismo tiempo, conformar mediante una ofensiva estatal de resocialización un nuevo sujeto acorde al orden que se estaba configurando, los jóvenes debían atravesar ese proceso para poder cumplir su rol. La concreción de este doble objetivo requirió entonces de una primera instancia, en la que la jerarquía militar tuvo que admitir la existencia del joven como sujeto político que debía ser desactivado, junto a otras en las que configuró el nuevo sujeto, disciplinado y controlado, y, finalmente, en el marco del diálogo político ensayó las primeras experiencias concretas de su incorporación al entramado institucional ${ }^{43}$.

Dado la centralidad de los jóvenes en el proyecto militar, las máximas autoridades no los asociaron directamente a la subversión. Aun cuando en el marco de la avanzada represiva se configuró y se instaló en la sociedad una mirada sospechosa sobre los jóvenes en la que se vinculó "drogadicción, delincuencia y subversión” y "juventud, universidad y subversión” criminalizado sus espacios de sociabilidad ${ }^{44}$, Luciani ha demostrado que la jerarquía militar no tuvo ese discurso estigmatizante. Muy por el contrario, la imagen sobre los jóvenes se tradujo en una apelación a la juventud blanca -en el sentido de pensarla como constituida por sujetos puros que iban a salvar a la humanidad- símbolo de futuro, esfuerzo y trabajo ${ }^{45}$. Sin embargo, como la juventud era una potencialidad requería de tutores que la hicieran realidad y evitaran que los jóvenes se dejaran llevar por los peligros que los acechaban y perdieran su camino. Así, la familia, la escuela, la universidad eran lugares que debían contenerlos, resguardarlos, defenderlos de peligros siempre ajenos a su existencia y supuesta esencia ${ }^{46}$. De esta manera, la mirada condescendiente y paternalista se complementó con la idea de jóvenes pasivos y vulnerables que adolecían de capacidad de acción, de reflexión, de toma de decisiones.

\section{La experiencia de los jóvenes}

Llegados por motivos y caminos diversos (la militancia católica, la búsqueda de un espacio en donde canalizar las ansias de participación, y/o la solidaridad con detenidos o desaparecidos) los jóvenes de ayer dieron sus primeros pasos en la militancia política en un contexto represivo y en el seno de la APDH. Educados en la aquiescencia y aceptación acrítica de lo existente con la amenaza, evidente o

42 García Delgado, op. Cit.

43 Luciani, op. Cit.

44 Valeria Manzano, "Política, cultura y el "problema de las drogas" en la Argentina, 1960-1980s", Apuntes de investigación del CECYP, Vol. 24, 2014, pp. 51-78.

45 Luciani, op. Cit.

${ }^{46}$ Ibid. 
velada, de represión ante cualquier posible contestación, ellos decidieron apartarse del mandato oficial e incorporarse voluntariamente en la lucha clandestina por la caída del régimen. Sus testimonios permiten pensar su participación en el "Seminario Juvenil" como una instancia de socialización política en la que adquirieron saberes teóricos (ideológicos, discursivos, históricos, etc.) y prácticos (destrezas, habilidades, know-how, etc. ${ }^{47}$. En este apartado, analizo cuáles fueron esos aprendizajes y cómo influyó en este proceso de socialización el contexto represivo, el perfil político-ideológico de la organización y la edad de las personas involucradas.

Aquellos jóvenes, hoy adultos, ya no participan en la institución (de la que se alejaron por motivos políticos hace ya varios años) ni en ninguna de las diversas organizaciones que actúan actualmente en la escena local. A pesar del actual distanciamiento, reconocen la trascendencia que tuvo su pasaje por la APDH en la trayectoria de sus vidas.

Nos cuidaban mucho. Nos pasaban a buscar para ir a la reunión y nos traían, y esperaban hasta que estuviéramos adentro (...) no éramos muchos, entrábamos en una mesa. Ahora hay mucho vedetismo, muy mediático. Antes no era así. Era una unidad de corazón. Los viejos son lo más. A mí no se me ocurriría faltarles el respeto. Llegar al juicio que se llegó [en 2008 se realizó en Neuquén el juicio por la desaparición de Oscar Alfredo Ragni, hijo de este matrimonio], verlos a Oscar [Ragni] e Inés [Rigo de Ragni] para mí fue... fue muy emotivo ver a los viejos.... Bueno, por fin, si les llega a pasar algo, hay un pequeño capítulo que van a poder cerrar ${ }^{48}$.

Tengo muchísimo respeto y afecto por quienes conformaron la APDH. Creo que haber militado en plena dictadura militar te hace mirar las cosas desde otro lugar. Sin lugar a dudas. Entonces, con mucha gente con la que hoy tengo diferencias tengo eso tan enorme, tan enorme, que es imposible que lo tape. Porque yo no adhiero a muchas cosas de la asamblea hoy, si no estaría trabajando ahí, pero tengo una profunda gratitud y profundo respeto. Que se yo... nosotros salíamos de la reunión a las once de la noche en plena dictadura militar y sin saber si llegábamos vivos o no, si nos estaban esperando, quién quedaba en cada casa, salir de a poquitos, mirar para atrás, quién se queda con uno, quién se queda con el otro (...) era poner el cuerpo y la vida ${ }^{49}$.

Como se desprende de los fragmentos, persiste entre quienes pertenecieron a la APDH un vínculo estrecho, afectuoso e incluso familiar -Beatriz menciona a los adultos como "los viejos"- que trasciende las diferencias políticas actuales. La cita de Beatriz es particularmente interesante porque incorpora una comparación entre la militancia de ayer y la de hoy que deja traslucir una nostalgia por valores como el respeto y la empatía que considera perdidos. Así, no es casual que el contraste entre "la unidad de corazón" del pasado y el "vedetismo" y la exposición mediática del presente, estén vinculados en el relato al juicio de 2008 (realizado un año antes de la entrevista) ya que en esa oportunidad Oscar (uno de los adultos mencionados) fue increpado en una manifestación en la que militantes allegados a la organización HIJOS cuestionaba la realización de los juicios. Entonces, este hecho, y las diferencias entre las organizaciones de derechos humanos frente a la realización de esos juicios, ayudan a comprender la

\footnotetext{
47 Entiendo a la socialización política como un proceso social dinámico e históricamente situado que no consiste en la adquisición pasiva y acrítica de conocimientos sino en la generación de un intercambio donde cada sujeto interactúa con su medio y con agentes de diverso tipo María Jesús Funes, "Socialización política y participación ciudadana. Jóvenes en dictadura y jóvenes en democracia", Revista de estudios de Juventud, Número Extraordinario, Vol. 1, 2003, pp. 57-76.

48 Beatriz, Entrevista realizada por la autora. Neuquén, 20 de abril de 2009.

Durante el año 2008 se realizó en Neuquén el primer juicio oral a ocho represores por la desaparición de Oscar Alfredo Ragni y otros 16 casos de privaciones ilegales de la libertad y tormentos. Ragni estuvo detenido y fue torturado en el centro clandestino conocido como La Escuelita, que funcionó en el batallón militar de la capital provincial durante la dictadura. Su madre, Inés Rigo -integrante de Madres de Plaza de Mayo filial Alto Valle de Río Negro y Neuquén- y su padre Oscar Ragni, miembro de la Corriente de Militantes de Derechos Humanos, pertenecieron a la APDH Neuquén y Alto Valle durante la dictadura.

${ }^{49}$ Susana, op. Cit.
} 
contraposición que marca la entrevistada. En ese "no se me ocurriría faltarles el respeto" es posible identificar su rechazo al incidente en concreto, pero también a la incomprensión -imperante en los sectores que rechazan los juicios ya sea en la sociedad en general o en organizaciones allegadas al propio movimiento de derechos humanos local- sobre el impacto del juicio en este matrimonio que finalmente podría "cerrar un pequeño capítulo" de sus vidas.

Por otra parte, el respeto también es para los compañeros con quienes se militó en un contexto de alto riesgo en el que el cuidado del otro, la confianza, la lealtad, la unidad, y la decisión de "poner el cuerpo y la vida" eran valores centrales y actitudes imprescindibles. Como ha demostrado Della Porta ${ }^{50}$, la clandestinidad y la emoción por los peligros compartidos impactan fuertemente en las relaciones entre los miembros de una organización. La intensidad y durabilidad de estos vínculos ha sido explicada tanto por la identificación afectiva entre los miembros como por la juventud de las personas involucradas. Y las experiencias aquí analizadas reúnen ambas condiciones. A pesar de producirse durante la dictadura o quizás porque se vivía bajo un régimen dictatorial, quienes militaron en la APDH forjaron vínculos que han trascendido en el tiempo y en el espacio conformando una familia, entendida como la unión de quienes comparten un objetivo político. Para estas entrevistadas la fortaleza de los lazos se vio, a su vez, reforzada por el hecho de estar atravesando una etapa como la juventud caracterizada por la búsqueda de la independencia emocional de la familia y en la que la lealtad al grupo de iguales es especialmente fuerte.

El paso de los jóvenes por la APDH no sólo les permitió aprehender ciertos valores y una actitud de entrega y compromiso sino también forjar una identidad militante. La necesidad de poseer una concepción del mundo que dé respuesta a los interrogantes ante la vida y permita definirse y diferenciarse es un elemento central de la participación juvenil ${ }^{51}$, y esta experiencia no fue una excepción. En un contexto marcado por la incertidumbre y la ausencia de referentes ${ }^{52}$, la APDH ofrecía un marco para la acción con una concepción del mundo clara y precisa que permitía enfrentarse a las dudas y la confusión del mundo adulto. Como mencioné anteriormente, el discurso de la APDH basado en la defensa de los derechos humanos reinstaló al ciudadano en su calidad de sujeto político y, desde ese lugar, marcó el límite al poder omnipotente del Estado. A pesar de que el mensaje y la concepción de la APDH distaban de ser revolucionarios (la declaración de los Derechos del Hombre es la fuente más citada en los documentos), la represión y la desciudadanización imperantes los convirtieron en distuptivos. Lo que en otro contexto hubiera sido interpretado como el simple ejercicio de una ciudadanía de derecho, la no vigencia del Estado de Derecho lo transformó en una práctica de ciudadanía de hecho, propia de experiencias ciudadanas más sustanciales y robustas.

[participar en la APDH] Era tan importante, era tan relevante porque lo que se estaba jugando era la diferencia entre poder encontrar a alguien y no encontrarlo. Entonces, el discurso tenía que ser impecable. Y el tipo que ponía la firma sabía por qué la ponía. A pesar de que se jugaban cosas muy importantes, algunos ponían el DNI, otros sólo firmaban... era valioso, la palabra era valiosa (...) Era de mucha responsabilidad lo que tenías que decir porque lo que estabas cuidando era muy relevante, se trataba de una institución para que no se entendiera, como decían los milicos, que se estaba infiltrado por lo subversivos, los que veían subversivos por todos lados, tenías que ser impecable y no por eso eras un boludo o un gris, o un flojo, si no había nadie, si eras vos el que estaba poniendo tu propia cara ${ }^{53}$.

\footnotetext{
50 Donatella Della Porta, "Las motivaciones individuales en las organizaciones políticas clandestinas", Pedro Ibarra y Benjamín Tejerina (eds.), Los movimientos sociales. Transformaciones politicas y cambio cultural, Madrid, Trotta. 1998, pp. 219-242.

51 Jesús Funes, op. Cit.

52 Lechner, op. Cit.

53 Juana, op. Cit.
} 
Aquí aparece nuevamente la trascendencia de la tarea asumida y, en consecuencia, la seriedad y responsabilidad con la cual era desarrollada. Como se desprende de la cita el compromiso asumido tenía más de un destinatario. En primer lugar, estaban las víctimas directas del terrorismo de Estado, es decir, los desaparecidos, los presos y sus familiares. En segundo término, estaban las personas que colaboraban con la APDH y que al hacerlo confiaban "su nombre, su firma, o su DNI" -en última instancia sus vidasa ellos, los militantes, y a la institución. Esta confianza conllevaba una gran responsabilidad ya que todavía en 1980/1 la vinculación con la defensa de los derechos humanos podía ser peligrosa y sospechosa. Por último, estaba el compromiso con la propia institución. "Ser impecable" en el discurso, mantener el "buen nombre" de la APDH implicaba medir lo que se decía y hacía para evitar caer en las trampas de la dictadura que vigilaba a las organizaciones e incluso las acusaba aunque no tuviera fundamentos ${ }^{54}$.

El lento renacer de la política a partir de la derrota en la Guerra de Malvinas atrajo más personas a la APDH y al "Seminario Juvenil" e hizo que sus actividades devinieran en convocatorias masivas. Sin embargo, también aportó elementos que exacerbaron tensiones existentes provocando posteriormente la fractura del núcleo central y el nacimiento de la delegación local de la Asociación Madres de Plaza de Mayo $^{55}$. La nueva coyuntura también afectó a este grupo de jóvenes militantes. Algunos siguieron trabajando en la organización unos años más para abandonarla en el marco de la desmovilización que comenzó hacia 1987, otros tomaron nuevos rumbos -como aquellos que se incorporaron a la Confederación Mapuce ${ }^{56}$, y hubo quienes empezaron a dividir su tiempo entre la militancia en defensa de los derechos humanos y la participación en los nuevos espacios que lentamente comenzaron a recuperarse como la organización gremial y universitaria.

Llega Alfredo Bravo. Se hizo una reunión en el salón parroquial. Lo trajo la APDH que fue el organismo que permitió que ATEN [Sindicato Único de los Trabajadores de la Educación en Neuquén] se organizara. Cuando se conforma la comisión directiva nadie quería dar el nombre, pero había que hacerlo. Éramos pocos los que nos animamos a poner el nombre porque por más que no quisiéramos sabíamos que al otro día estabas en la lista en la cana ${ }^{57}$.

P: Cuando llegué a la iglesia tenía 17 años, te encontrabas con un a panorama que no conocías, era muy particular, teoría de la liberación, compromiso con los pobres, la lucha contra el sistema. Y ahí descubrimos esa dimensión política que nos ayudó después a organizarnos como mapuces y que costó una crisis muy fuerte con la iglesia porque la misma iglesia que nos había formado políticamente era la iglesia que empezamos a cuestionar por el rol que cumplió históricamente (...) cuestionar a De Nevares era muy violento en ese momento porque él había recibido a las madres de plaza de mayo, funda la APDH.

E: Y al plantear la existencia de sus derechos, ¿cuál fue la actitud de la APDH?

P: Nosotros éramos parte de la juventud de la APDH. Para nosotros fue un salto muy natural militar en la iglesia a involucrarnos en la política de la APDH porque era parte de los ideales que se proponían. La relación con la APDH fue una de las relaciones más estrecha que hemos mantenido en todos estos años. Es con la organización que hemos trazado un lazo histórico profundo, siempre nos hemos sentido apoyados $(\ldots)^{58}$.

\footnotetext{
$54 \mathrm{Al}$ igual que sus pares en otros escenarios, la APDH Neuquén y Alto Valle fue acusada de tener contactos internacionales y "subversivos" y tuvo que esclarecer públicamente los verdaderos fines de la institución y explicar las actividades que realizaban en más de una oportunidad.

55 Azconegui, op. Cit.

56 Se mantiene el término "mapuce", sin h intermedia, tanto en singular como en plural, de acuerdo al grafemario Ragilew que adoptó autónomamente ese pueblo

57 Susana, op. Cit.

58 Pablo, Entrevista realizada por la autora. Neuquén, 15 de agosto de 2008.
} 
Como ha demostrado McAdam ${ }^{59}$, la militancia de alto riesgo tiene un potencial transformador que se traduce tanto en efectos actitudinales como estructurales. Desde el punto de vista actitudinal, la experiencia puede generar mayor compromiso, estableciendo así las bases para una participación continua. Como refleja el primer fragmento, la joven militante era consciente de los peligros que corría al ser uno de los miembros de la flamante Comisión Directiva del gremio docente ATEN, creado en agosto de 1982, pero decide participar porque "había que hacerlo". ¿De dónde surge ese deber ser? Es posible inferir que su pertenencia al "Seminario Juvenil" en ese momento, su inmersión en el ideario de la organización y su socialización en ese espacio fueran todos elementos significativos al considerar esa necesidad como una obligación y tomar la determinación de participar. Este no fue un caso aislado, otros optaron por la participación vecinal, mapuce y/o universitaria. El carácter apartidista de la APDH local puede haber influido en que ninguna de estas trayectorias individuales derivara en la militancia partidaria ${ }^{60}$. Más allá del espacio elegido para continuar su militancia, este grupo de jóvenes formados durante la dictadura en el seno de la APDH local se insertaron en las diversas organizaciones que desarrollaron en los años ochenta y noventa una "contra-cultura de la protesta" en Neuquén ${ }^{61}$ y, en consecuencia, fueron parte constitutiva de la misma.

Por otro lado, los efectos de la militancia de alto riesgo no son meramente actitudinales. La experiencia dejó a los jóvenes vinculados tanto a redes de relaciones personales como a organizaciones que ayudaron a mantener su activismo. Como se desprende del segundo fragmento, el contacto con la APDH y su apoyo fue de gran valor para los jóvenes mapuces quienes, luego de haber descubierto la dimensión política de su identidad mapuce en el seno de la iglesia católica, decidieron confrontar públicamente con ella y con la figura del obispo Jaime de Nevares.

\section{Consideraciones finales}

Las reglas del juego establecidas por la junta militar sostuvieron una dinámica social y política caracterizada por su privatización y redefinición. Si bien es cierto que la política quedó reducida a la mera administración en un escenario velado y vedado, al cual sólo pudieron acceder ciertos grupos, también lo es que esas circunstancias permitieron el surgimiento de nuevos actores, como la APDH, que ejercieron la función de oposición aislada. El período analizado, 1980-1981, resulta interesante porque permite ver cambios tanto en la esfera de poder como en las filas de la oposición.

En ese momento de redefiniciones políticas y estratégicas, la juventud se convirtió en un actor clave para quienes estaban diseñando los pasos que se iban a seguir. Tanto las máximas autoridades militares, como la APDH, veían en los jóvenes una pieza clave para la construcción del futuro nacional. Sin embargo, las coincidencias terminaban allí. Mientras que la jerarquía militar consideraba al joven como un sujeto pasivo y amenazado que debía ser protegido de diversos peligros, la experiencia del "Seminario Juvenil" en Neuquén lo posicionaba en un lugar protagónico con capacidad de reflexión y de acción, aunque pasible de ser acompañado y guiado en sus decisiones. Asimismo, frente al generalizado predominio de pautas de sociedad de consumo, individualismo y baja motivación respecto del sistema político -actitudes resultantes del proceso de resocialización inducido por el régimen autoritario-62, esta organización instaba al compromiso con el otro y con el sistema. Finalmente, si las

\footnotetext{
59 Mc Adam, op. cit

${ }^{60}$ Esto marca una diferencia con los jóvenes católicos con quienes compartían muchos espacios y actividades (dada la estrecha relación entre la APDH y el catolicismo en Neuquén) quienes sí incursionaron en las listas de los partidos políticos en las elecciones de 1983. Por otra parte, queda pendiente analizar la experiencia de otras delegaciones de la APDH y las trayectorias de sus integrantes para poder ver la especificidad neuquina.

${ }^{61}$ Ariel Petruccelli, Docentes y piqueteros. De la buelga de ATEN a la pueblada de Cutral Có, Buenos Aires, El cielo por asalto / El Fracaso, 2005.

${ }^{62}$ García Delgado, op. Cit,
} 
organizaciones defensoras de los derechos humanos comenzaron la refundación de la comunidad política y reinstalaron la idea de un sujeto de derecho, con "derecho a tener derechos" 63 , podemos agregar que fue desde sus prácticas de "ciudadanos de hecho" que estos militantes cuestionaron al régimen militar y sus políticas, al tiempo que lucharon para recuperar su condición de ciudadanos de derecho.

Por otra parte, el paso por la APDH y su rol activo en el "Seminario Juvenil" organizado en Neuquén dejaron una huella imborrable en aquellos jóvenes. El contexto represivo, su juventud y la afectuosidad de las relaciones que se gestaron en el seno de esta organización sentida como una gran familia, son elementos que contribuyeron para que esa experiencia tuviera efectos de largo plazo. La reconstrucción y el análisis de algunas trayectorias individuales permite observar un proceso de resocialización política y el comienzo de "carreras militantes" que continuaron posteriormente en organizaciones vecinales, mapuces, sindicales y universitarias. Así, al constituirse en una instancia de formación para jóvenes, la APDH local incidió en la reorganización social y política postmalvinas al tiempo que contribuyó, a través de la inserción de militantes consustanciados con sus ideales y prácticas, a dar forma a la "contra-cultura de la protesta" que se desarrolló en los años ochenta y noventa en Neuquén.

\section{Bibliografía}

Águila, Gabriela; Garaño, Santiago; Scatizza, Pablo (coord), Represión estatal y violencia paraestatal en la bistoria reciente argentina: Nuevos abordajes a 40 años del golpe de Estado, La Plata, UNLP, 2016.

Alonso, Luciano, "Terror de Estado y luchas pro derechos humanos en Argentina: las dimensiones ocluidas", Ayer, Asociación de Historia Contemporánea, N 107, 2017, pp. 99-124.

Alonso, Luciano, Luchas en plazas vacias de sueños. Movimiento de derechos humanos, orden local y acción antisistémica en Santa Fe, Prohistoria Ediciones, Rosario, 2011.

Azconegui, María Cecilia, "La Iglesia Católica y la APDH neuquinas frente al terrorismo de Estado", Muñoz Villagrán, Jorge (coord.), Pedagogía política en Don Jaime de Nevares, Neuquén, Universidad Nacional del Comahue, 2012, pp. 256-288.

Azconegui, María Cecilia, "Desobediencia debida. La defensa de los derechos humanos en el Alto Valle y Neuquén, 1976-1983", Kotler, Rubén (comp.), En el país del si me acuerdo. Los orígenes nacionales y transnacionales del movimiento de derechos humanos en Argentina: De la dictadura a la transición, Buenos Aires, Imago Mundi, 2014, pp. 47-77.

Bourdieu, Pierre, Sociología y cultura, México, Grijalbo, 1978

Canelo, Paula. La política secreta de la última dictadura militar argentina, Buenos Aires, Edhasa, 2016.

Catoggio, María Soledad, Los desaparecidos de la Iglesia. El clero contestatario frente a la Iglesia, Siglo XXI, 2016.

Chaves, Mariana, Estudios sobre juventudes en Argentina 1. Hacia un estado de la cuestión, La Plata, Red de Investigadora/es en Juventudes Argentina y Editorial de la UNLP, 2009.

Crenzel, Emilio, "Los derechos humanos, una verdad evidente de la democracia en la Argentina", Estudios, $\mathrm{N}^{\circ}$ 29, 2013, pp. 73-91.

Della Porta, Donatella, "Las motivaciones individuales en las organizaciones políticas clandestinas", Ibarra, Pedro; Tejerina, Benjamín (eds.), Los movimientos sociales. Transformaciones politicas y cambio cultural, Madrid, Trotta, 1998, pp. 219-242.

Franco, Marina, El final del silencio. Dictadura, sociedad y derechos bumanos en la transición (Argentina, 1979-1983), Buenos Aires, FCE, 2018.

García Delgado, Daniel, "Nuevos patrones de participación política en procesos de transición a la democracia: el caso argentino", Oszlak, Oscar (comp.), 'Proceso', crisisy transición democrática, Buenos Aires, CEAL, 1984.

${ }^{63}$ González Bombal y Sondereguer, op. Cit, 
González Bombal, Inés; Sondereguer, María, "Derechos humanos y democracia”, Jelín, Elizabeth (comp.), Movimientos Sociales y Democracia emergente, Buenos Aires, CEAL, 1987, pp. 85-112.

Jelin, Elizabeth, "La política de la memoria: el movimiento de derechos humanos y la construcción democrática en la Argentina", Acuña, Carlos et. al., Juicio, castigos y memorias. Derechos bumanos y justicia en la política argentina, Buenos Aires, Nueva Visión, 1995, pp. 101-146.

Jesús Funes, María, "Socialización política y participación ciudadana. Jóvenes en dictadura y jóvenes en democracia", Revista de estudios de Juventud, 2003, Número Extraordinario 1, pp. 57-76.

Kotler, Rubén, Huellas de la memoria en la resistencia antibussista. Historia del movimiento de derechos humanos en Tucumán 1976-1999, Imago Mundi, Buenos Aires, 2018.

Landi, Oscar; González Bombal, Inés "Los derechos en la cultura política”, Acuña, Carlos et. al., Juicio, castigos y memorias. Derechos humanos y justicia en la política argentina, Buenos Aires, Nueva Visión, 1995, pp. 147-192.

Lechner, Norberto, “¿Qué significa hacer política?”, Documento de Trabajo, FLACSO, 1982.

Leis, Héctor, El movimiento por los derechos bumanos y la política Argentina, Buenos Aires, CEAL, 1989.

Lida, Miranda, "Las masas católicas en los años de la dictadura, 1976-1982", Entrepasados, 2008, 34, pp. 55-73. Luciani, Laura, Jwventud en dictadura: representaciones politicas, experiencias juveniles e Rosario (1976-1983), La Plata, Posadas, Los Polvorines, UNLP-UNS;-UNGS, 2017.

Manzano, Valeria, "Política, cultura y el "problema de las drogas" en la Argentina, 1960-1980s", Apuntes de investigación del CECYP, 2014, 24, pp. 51-78.

Mc Adam, Doug; Mc Carthy, John; Zald, Mayer (comp.) Movimientos Sociales: perspectivas comparadas, Madrid, Istmo, 1999.

McAdam, Doug, “The Biographical Consequences of Activism”, American Sociological Review. 1989, 54, pp. 744760.

Oviedo Silvina; Solis Ana Carol, Violencia institucionalizada y formas de resistencia social: los organismos de Derechos Humanos en Córdoba durante la dictadura, Tesis de Licenciatura en Historia, UNC, Inédito, 2006.

Perrén, Joaquín, "Erase una vez en la Patagonia - Luces y sombras de la economía neuquina (1958-1991)", Observatorio de la Economía de la Patagonia, 2007, Disponible en internet http://www.eumed.net/oe-pat/.

Petruccelli, Ariel, Docentes y piqueteros. De la buelga de ATEN a la pueblada de Cutral Có, Buenos Aires, El cielo por asalto / El Fracaso, 2005.

Scatizza, Pabl, Un Comabue violento. Dictadura, represión y juicios en la Norpatagonia argentina, Buenos Aires, Prometeo Libros, 2016.

Scocco, Marianela, La conformación del movimiento de derechos humanos de Rosario (1970-1985), Tesis doctoral en Historia, UNR, mimeo, 2018.

Yannuzzi, María de los Ángeles, Politica y Dictadura. Los partidos politicos y el 'Proceso de Reorganización Nacional', 1976-1982, Rosario, Editorial Fundación Ross, 1996.

\section{Fuentes documentales}

APDH, Informe de la delegación Alto Valle y Nenquén, 8 de agosto de 1980.

APDH, Resumen del encuentro de delegaciones, 18 de septiembre de 1981.

APDH Neuquén y Alto Valle, Subcomisión Seminario Juvenil. Delegación Alto Valle, mayo y agosto de 1981.

Río Negro, "Presentación de familiares de personas desaparecidas, Río Negro, General Roca, 1980, p. 13.

\section{Fuentes orales}

Beatriz, Entrevista realizada por la autora. Neuquén, 20 de abril de 2009.

Juana, Entrevista realizada por la autora. Neuquén, 30 de julio de 2008.

Pablo, Entrevista realizada por la autora. Neuquén, 15 de agosto de 2008.

Susana, Entrevista realizada por la autora. Neuquén, 29 de mayo de 2009. 